Uludag Univ. J. Fac. Vet. Med.

32 (2013), 2: 1-6

\title{
Tavşanlarda Orta Dönem Gebeliklerin Sonlandırılmasında Kullanılan Aglepriston'un Bazı Oksidatif Stres Parametreleri Üzerine Etkisi
}

Füsun AK SONAT ${ }^{1}$

\author{
Deniz BAĞDAŞ² \\ Gözde R. ÖZALP*
}

Geliş Tarihi: 06.11.2013

Kabul Tarihi: 19.03.2014

\author{
Zülfiye GÜL ${ }^{3}$
}

zet: Aglepriston son yıllarda küçük hayvan hekimliğinde abort indüksiyonları için başarıyla kullanılabilen bir progesteron reseptör antagonistidir. Yapılan klinik çalışmalarda ilacın hiçbir yan etkisinin olmadığı belirtilmişse de oksidatif stres üzerine etkisi hakkında bilgi bulunmamaktadır. Bu çalışmada tavşanlarda orta dönem gebeliklerin sonlandırılması için uygulanan aglepristonun, oksidatif stres parametreleri olan Malondialdehit (MDA), Süperoksit Dismutaz (SOD) ve redükte Glutatyon (GSH) üzerine etkisinin araştırılması amaçlandı. Çalışmada kullanılan 12 aylık yaşta 15 adet Yeni Zelanda Beyaz tavşanı kontrollü olarak çiftleştirildi ve çiftleştirildikleri gün gebeliklerinin 0 . günü olarak kabul edildi.

Gebe olan tavşanlar rastgele üç gruba ayrıldı. Grup I (kontrol) tavşanlarına gebeliğin 15 . ve 16 . gününde $1 \mathrm{ml} / 3 \mathrm{~kg}$ olacak şekilde $\% 0.9 \mathrm{NaCl}$, Grup II tavşanlarına gebeliğin 15. gününde, Grup III tavşanlarına ise gebeliğin 15 . ve 16. gününde $10 \mathrm{mg} / \mathrm{kg}$ dozda subkutan (s.c.) olarak aglepristone (Alizin ${ }^{\circledR}$ ) enjeksiyonu yapıldı. Tavşanlardan alınan kan örneklerinde MDA, SOD ve GSH ölçümleri yapıldı. Grup III de MDA seviyesinde artış saptandı. Bu artış Grup I $(\mathrm{p}<0.01)$ ve Grup II ye $(\mathrm{p}<0.05)$ göre anlamlı bir şekilde yüksek çıkmıştır. SOD aktivitesinde Grup II ve Grup III'de azalma saptanmıştır. Kontrol grubuna kıyasla SOD'daki bu düşüş istatistiki olarak anlamlı $(\mathrm{p}<0.01)$ bulunmuştur. GSH ise Grup I'e kıyasla diğer 2 grupta da azalmıştır. Grup III'ün GSH düzeyindeki bu düşüş Grup I ( $\mathrm{p}<0.001)$ ve Grup II’ye $(\mathrm{p}<0.01)$ göre istatistiksel olarak anlamlıdır. Bu sonuçlar abort indüksiyonunda kullanılan aglepristonun çift enjeksiyon yapıldığında oksidatif stresi tetiklediği ve antioksidan enzim aktivitelerini değiştirdiğini düşündürmektedir.

Anahtar Kelimeler: Aglepriston, Süperoksid dismutaz, Malondialdehit, Glutatyon, Tavşan.

\section{The Effects of Aglepristone on Some Oxidative Stress Parameters Used in Midgestation Terminations in Rabbits}

\begin{abstract}
Aglepristone is a safe and effective abortifacient, which is being widely used in small animal practice during the last years. Although no side effetcs have been reported in clinical studies, there is no information available about the effects of aglepristone on oxidative stress parameters. The objective of this study was to investigate the effects of aglepristone treatment on oxidative stress parameters, which are Malondialdehyt (MDA), Superoxide Dismutase (SOD) ve reduced Glutathione (GSH), in mid-gestation termination in rabbits. Fifteen healthy New Zealand White rabbit, 12 months of age, were included the the study. They were given to fertile bucks and the mating day was recorded as the 0 day of pregnancy. The does were randomly divided into

1 Yrd.Doç.Dr., Uludağ Üniversitesi Veteriner Fakültesi Fizyoloji Anabilim Dalı Görükle Kampüsü/BURSA

2 Araş.Gör.Dr., Uludağ Üniversitesi Tıp Fakültesi Deney Hayvanları Yetiştirme Uygulama Merkezi Görükle Kampüsü /BURSA

3 Araş.Gör., Uludağ Üniversitesi Tıp Fakültesi Farmakoloji Anabilim Dalı Görükle Kampüsü/BURSA

4* Doç.Dr.,Uludağ Üniversitesi Veteriner Fakültesi Doğum ve Jinekoloji Anabilim Dalı Görükle Kampüsü/BURSA, rgozalp@uludag.edu.tr
\end{abstract}


three groups. In Group I (control) the does were injected with $0.9 \% \mathrm{NaCl}$ at dose of $1 \mathrm{ml} / 3 \mathrm{~kg}$ on day 15 and 16 post-mating. In Group II and Group III, aglepristone (Alizin ${ }^{\circledR}$ ) was applied at a dose of 10mg/kg dose of subcutaneously, on day 15 and on days 15-16 days post-mating, respectively. MDA, SOD and GSH levels were measured from collected blood samples. A marked increase of MDA in Group III, was statistically significant with Group I $(p<0.01)$ and Group II $(p<0.05)$. On the other hand contrary decrease had been detected in SOD and GSH in Groups II and III which is statistically significant to control group $(\mathrm{p}<0.01)$. This decrease in GSH in Group III, was also significant between Group I ( $\mathrm{p}<0.001)$ and Group II ( $\mathrm{p}<0.01)$.

The results had suggested that the the application of aglepristone on two consecutive days in abort induction could both trigger oxidative stres and change antioxidant enzyme activities.

Key Words: Aglepristone, Superokside dismutase, Malondialdehyt, Glutathione, Rabbit.

\section{Giriş}

Progesteron reseptör antagonisti olan aglepristonun küçük hayvan hekimliğinde sik ve güvenle kullanılan bir medikal ajan olduğu yapılan araştırmalarda belirlenmiştir ${ }^{13-18,21,22,36}$. Aglepriston anti-progesteron aktivitesine sahip sentetik bir steroid olup ve Avrupa'da Fransa, Belçika, İsviçre, İspanya, İtalya, Almanya, Yunanistan, Portekiz, Hollanda, İngiltere, Polonya, Macaristan, Çek Cumhuriyeti, Slovakya'da; Latin Amerika'da Brezilya, Kolombiya, KostaRika ve Meksika'da; Pasifikte Avustralya ve Yeni Zellanda'da küçük hayvan hekimliğinde kullanılan ilk lisanslı veteriner preparatıdır. Tavşanlarda orta dönem gebeliklerin sonland1rilmasinda ve implantasyonun engellenmesinde kullanımı da detaylı olarak araştırılmış ve oldukça başarılı sonuçlar elde edilmiştir ${ }^{28-30}$.

Tavşanlarda çiftleşmeden sonraki 8,9 ve 10. günlerde yapılan mifepriston uygulamalar1nın embriyo rezorpsiyonuna yol açarak gebeliği önlediği bildirilmiştir² ${ }^{2}$ Trichosanthiskirilowii kökünden saflaştırılan bir protein olan Trichosanthin'in de çiftleşmeden sonraki 17-22. günlerinde intraperitoneal uygulamasının progesteron konsantrasyonunu düşürerek abortlara yol açtı̆̆ 1 bildirilmiştir ${ }^{33}$. Gebeliğin engellenmesi için tavşanlarda $\mathrm{PGF}_{2 \alpha}$ uygulamalar1 ${ }^{34}$, RU 486 ve anordrin kombinasyonları denenmiştir ${ }^{3-5}$ ancak bunların hiçbiri pratik sonuçlar vermemiştir ${ }^{22}$.

Antiprogestinlerin kimyasal yapısı yüksek oranda yapısal benzerlik gösterir ve progesteron reseptörlerine yarışmalı bağlanma özelliği gösterir. C17'de hidrofobik halka bölgesi reseptör bağlantısına yüksek oranda afinite gösterirken, C11'deki aromatik halka dimetilamino grubuyla transkripsiyonu baskılayan konformasyonel değişikliklere neden olur ${ }^{21}$. Aglepriston enjeksiyonundan sonra uterus reseptörleri için progesteron ile yarışır. Progesteron reseptörüne bağlandıktan sonra, progesteron reseptör antagonisti reseptörün yapısını yüksek afiniteyle stabilize eder ve uterus yetersiz stimüle olur. $\mathrm{Bu}$ progesteronun biyolojik etkilerini göstermesine engel olur ve fötal ölümlere yol açarak aborta neden olur. ${ }^{16,32}$.

Oksidatif stres serbest radikal veya reaktif oksijen türlerinin üretimi ile antioksidan sistem arasındaki dengenin kaybolması olarak tanımlanır ${ }^{9,11,23,26}$. Oksidatif streste artış, gebelik boyunca embriyonun veya fötusun gelişiminde değişikliklere neden olabilmektedir. Oksidatif stres, abortun şekillenmesi için patolojik bir zemin hazırlayabiliti ${ }^{25}$. Yapılan çalıșmalar, aşırı miktarda reaktif oksijen türlerinin (ROS) üretiminin oksidatif stresi arttırdığını göstermiştir. Bu durum ise çoğu biyokimyasal yolaklar vasıtasıyla serbest radikal üretimini arttırmaktadır ${ }^{7,38}$.

Serbest radikaller vücutta metabolizma sonucunda oluşabildiği gibi, çevre kirliliğ̣i, sigara dumanı, egzersiz, ateşli hastalıklar, iskemi, pestisitler, kontamine sular veya radyasyona maruz kalma sonucunda da meydana gelebilmektedir. Serbest radikaller yüksek oranda reaktif maddelerdir. Onlar biyolojik açıdan önemli olan hücre bileşenlerine zarar verebilir ve çeşitli hastalıklara sebep olabilir. Vücut için oldukça zararlı bileşiklerdir. Normal şartlarda serbest radikaller vücudumuzdaki Süperoksit Dismutaz (SOD), Glutatyon, Katalaz gibi antioksidan enzimler aracılığıyla nötralize edilirler. Bunların yanı sira beslenmemiz esnasinda gidalardan aldığımız E Vitamini, C vitamini, karotenler, flavanoidler, Glutatyon gibi antioksidanlarda serbest radikallerin ortadan kaldırılmasında önemli görevlere sahiptirler. Glutatyon gidalardan alınabildiği gibi vücutta alyuvarların yapısında da bulunan antioksidan bir bileşik$\operatorname{dir}^{6,7,10,24}$.

Sağlıklı bireylerde antioksidanlar ile serbest radikaller arasında hassas bir denge sözkonusudur. Bazı patolojik durumlarda örneğin abortus gibi oksidatif stres hizlanmakta, antioksidan mekanizma yavaşlamakta ve bu hassas denge bozulmaktadır. Bunun sonucunda ise 
DNA, proteinler, karbonhidratlar ve lipidler gibi vücuttaki tüm biyolojik moleküller etkilenmektedir. Bu oksidatif stres membran rupturu, karbonhidratlarda hasar, lipid peroksidasyon, protein oksidasyon gibi mutajenik, sitotoksik ve karsinojenik süreçlere neden olabilmektedir. ${ }^{1,7,20,35}$.

SOD, en etkin intraselüler enzimatik antioksidanlardan biridir. Bu enzim oksijenden ilk oluşan reaktif bir ürün olan süperoksit anyonunun moleküler oksijene ve daha az reaktif bir ürün olan hidrojen perokside dönüşünü katalize ederek radikallerin etkisini azaltmış olur. ${ }^{10,24}$

GSH, suda çözünen bir antioksidandır. Vücutta direkt olarak sistein, glisin ve glutamattan sentezlenmektedir. C vitamini ile sinerjik çalışır. Direk olarak serbest radikalleri temizlemesinin yanısıra; GPx ile birlikte enzimatik olarak da etki gösterir. GSH hücrelerde enzim ve diğer hücresel bileşenlerin redükte halde tutulmamaları için hayati rol oynar. Bir çok hücrede çok yüksek konsantrasyonlarda bulunan glutatyon, biyolojik membranları lipid peroksidasyonuna karşı korumaktadır. GSH en çok karaciğerde sentezlenir ve yaklaşı \% 40'1 safra ile atılır. Safradaki bu GSH diyetteki ksenobiyotiklere karşı vücudu korumaktadır ${ }^{6,10,24}$.

Oksidatif stresin şiddetinin değerlendirilmesinde çeşitli parametreler kullanılmaktadır. MDA da lipid peroksidasyonun bir göstergesi olarak s1klıkla kullanılmaktadır ${ }^{9,31}$.

$\mathrm{Bu}$ çalışmanın amacı, tavşanlarda orta dönem gebeliklerin sonlandırılmasında aglepristonun kullanımının oksidatif stres parametrelerine etkisini değerlendirmektir. Konuya ilişkin verilerin literatürde bulunmaması çalışmamızın önemini ve orjinalliğini vurgulamaktadır.

\section{Materyal ve Metod}

\section{Tavşanların Çiftleştirilmesi ve Gebelik Muayenesi}

Çalışma materyalini Uludağ Üniversitesi Deney Hayvanları Uygulama ve Yetiştirme Merkezinden alınan 12 aylık yaşta, 2800-3400 gr canlı ağırlıkta, 15 adet Yeni Zelanda Beyaz tavşanı oluşturmuştur. Çalışma için Uludağ Üniversitesi Hayvan Deneyleri Yerel Etik Kurulu'ndan onay alınd1 (2013-01/06). Hayvanlar bireysel kafeslerde barındırıldı. Tüm tavşanlar kontrollü olarak erkek tavşanların kafeslerine verildi ve 20 dakika içinde çiftleşmeler gerçekleşti. Kontrollü yapılan çiftleştirilme günü gebeliklerinin 0. günü olarak kabul edilerek, 14. günde transabdominal ultrasonografi ile gebelik teşhisi yapıldı (5-7,5 MHz linear array transducer; Siemens Sonoline Prima, Siemens Medical System, USA) Gebe olan tavşanlar rastgele üç gruba ayrild.

\section{Aglepriston Uygulamaları ve Kan Ör- neklerinin Toplanması}

Gebe tavşanlar her birinde 5 adet olacak şekilde 3 gruba ayrıldı. Grup I tavşanlarına kontrol amaçlı gebeliğin 15. ve 16. gününde aynı saatte \% $0.9 \mathrm{NaCl}, 3 \mathrm{ml} / \mathrm{kg}$ (Eczacıbaş1, Baxter, Türkiye) enjeksiyonu subkutan yapıldı. Grup II tavşanlarına aglepristone (Alizin, Virbac, Almanya) gebeliğin 15 . gününde $10 \mathrm{mg} / \mathrm{kg}$ dozda s.c. olarak bir sefer enjekte edildi. Grup III tavşanlarına aglepristone gebeliğin 15 . ve 16 . gününde aynı saatte $10 \mathrm{mg} / \mathrm{kg}$ dozda s.c.olarak enjekte edildi. Grup I ve Grup III tavşanlarından gebeliğin 17. günü, son enjeksiyondan 24 saat sonra; Grup II tavşanlarından 16. gün yine enjeksiyondan tam 24 saat sonra sentral kulak veninden, 30 gauge'lik kanüllerle kan örneği heparinli tüplere topland1. 5.000 rpm'de 10 dakika santrifüj edilen kan örneklerinden plazma ayrilıp analizler yapilıncaya kadar $-20^{\circ} \mathrm{C}^{\prime} \mathrm{de}$ sakland1.

\section{Plazma MDA ölçümü}

Malondialdehit (MDA) ölçümü için tavşan plazma örnekleri üzerine eşit miktarda \% 10'luk TCA (trikloro asetik asit) eklendi. Daha sonra vortekslenip $+4{ }^{\circ} \mathrm{C}$ ' de $4000 \mathrm{rpm}$ de 10 dakika santrifüj edildi. MDA ölçümü tiyobarbitürik asit (TBA) reaktivitesi metodu kullanılarak ölçüldü (27). Üst fazdan $0,5 \mathrm{ml}$ alınıp üzerine \% $0.67^{\prime}$ lik TBA çözeltisinden eklenip $+100^{\circ} \mathrm{C}$ 'de 1 saat 1sitıldı. Soğutulduktan sonra $546 \mathrm{~nm}$ de spektrofotometrede okundu. Veriler pikomol (pmol) / ml plazma cinsinden sunuldu.

\section{Plazma GSH ölçümü}

Redükte glutatyon ölçümü için tavşan plazma örnekleri üzerine eşit miktarda \% 10'luk TCA eklendi. Daha sonra vortekslenip $+4^{\circ} \mathrm{C}$ 'de $4000 \mathrm{rpm}$ de 10 dakika santrifüj edildi. Üst fazdan $0,5 \mathrm{ml}$ alınıp üzerine $2 \mathrm{~mL} \mathrm{0,3} \mathrm{M} \mathrm{Na}_{2} \mathrm{HPO}_{4}$, $2 \mathrm{H}_{2} \mathrm{O}$ ve $0,2 \mathrm{~mL}$ dithiobisnitro benzoik asit ilave edildi ${ }^{12}$. Örnekler $405 \mathrm{~nm}$. de spektrofotometrede okundu. Veriler mikromol $(\mu \mathrm{mol}) /$ $\mathrm{ml}$ plazma cinsinden sunuldu.

\section{Plazma SOD ölçümü}

Süperoksiddismutaz enzim aktivitesi ticari kit aracılığıyla ELISA yöntemine dayalı ölçüldü. Özetle ksantin/ksantinoksidaz sistemine 
ve nitrobluetetrazoliumun indirgenmesine dayanan yöntemle okundu ${ }^{37}$. Veriler ünite $(\mathrm{U}) / \mathrm{ml}$ plazma cinsinden sunuldu.

\section{İstatistiksel analiz}

Çalışmada istatistiksel analizlerde SigmaStat ${ }^{\circledR}$ (versiyon 2.03) programı kullanıld1. İstatistiksel değerlendirmeler tek yönlü ANOVA'y1 takiben Student-Newman-Keuls test kullanılarak yapıldı. Elde edilen veriler "ortalama \pm standart hata" şeklinde verildi. Anlamlılık P değeri ile gösterilerek, karşılaştırılan gruplar arasındaki değerlerin istatistiksel ölçüsü olarak sunuldu. P'nin 0.05 'den küçük olduğu değerler istatistiksel olarak anlamlı kabul edildi.

\section{Bulgular}

Deney gruplarından elde edilen MDA, GSH ve SOD değerleri Tablo-1 de sunulmuştur.

Tablo I: Gruplar arası plazma MDA, GSH ve SOD değerlerinin karşılaştırılması

Table I: Comparision of of plasma MDA, GSH and SOD levels in three groups.

\begin{tabular}{|c|c|c|c|}
\hline Parametreler & $\begin{array}{c}\text { Grup I } \\
\text { (Kontrol) }\end{array}$ & $\begin{array}{c}\text { Grup II } \\
\text { (Tek enj.) }\end{array}$ & $\begin{array}{c}\text { Grup III } \\
\text { (Çift enj.) }\end{array}$ \\
\hline MDA (pmol/ml) & $354,6 \pm 40,9$ & $433,3 \pm 34,3$ & $568,4 \pm 43,2^{a, c}$ \\
\hline GSH $(\mu \mathrm{mol} / \mathrm{ml})$ & $617,7 \pm 14,4$ & $555,2 \pm 33,9$ & $414,8 \pm 31,8^{b, d}$ \\
\hline SOD (U/ml) & $80,6 \pm 0,2$ & $75,8 \pm 1,5^{a}$ & $74,5 \pm 0,6^{a}$ \\
\hline
\end{tabular}

a $p<0.01$ Grup I ile karşılaştırılmıştır, $\quad$ b $p<0.001$ Grup I ile karşıılaştırılmışıtır,

c p $<0.05$ Grup II ile karşılaştırılmıştır, d $\mathrm{p}<0.01$ Grup II ile karşılaştırılmıştır.

Tabloda belirtildiği gibi dokulardaki lipid peroksidasyonun iyi bir göstergesi olan MDA seviyesi en düşük kontrol grubunda, en yüksek ise çift enjeksiyon Aglepriston uygulanan Grup III de bulunmuştur. Grup III deki bu artış grup I $(\mathrm{p}<0.01)$ ve Grup II ye $(\mathrm{p}<0.05)$ göre anlamlı bir şekilde yüksek çıkmıştır. Grup II, Grup I ile kıyaslandığında MDA seviyesinde yine bir artış söz konusu fakat bu artışta istatistiksel olarak önem bulunmamıştır. Aglepriston abort oluşturmasının yanı sıra, abortun oluşturduğu etkiden daha fazla oksidatif stres parametrelerini arttırıcı bir güce sahip olabilir.

Dokularda nonenzimatik bir antioksidan olan GSH ise grup I'e kıyasla diğer 2 grupta da azalmıştır. Çift enjeksiyon yapılan Grup III'ün
GSH düzeyindeki bu düşüş Grup I $(p<0.001)$ ve Grup II ye $(p<0.01)$ göre önem arz etmektedir. En yüksek GSH seviyesi Grup I'de en düşük GSH seviyesi ise Grup III'de bulunmuştur.

Vücutta enzimatik bir antioksidan olan SOD, en yüksek Grup I'de bulunmuştur. Grup II ve III'deki değerler daha düşük çıkmıştır. Grup II ve Grup III'de SOD aktivitesindeki bu düşüş kontrol grubuna kıyasla istatistiki olarak anlaml1 $(\mathrm{p}<0.01)$ bulunmuştur.

\section{Tartışma}

Çalışmadan elde edilen bulgulara göre; çift enjeksiyon yapılan grupta, kontrol ve tek enjeksiyon yapılan gruba kiyasla MDA seviyesindeki artışın önemli olup, tek enjeksiyon grubu ile kontrol grubu arasinda farkın bulunamaması yalnızca abortun değil aborta sebep olan Aglepristonun oksidatif stres markerlarını arttırmasının söz konusu olabileceğini akla getirmektedir. Yani Aglepriston abort oluşturmas1nın yanı sıra, abortun oluşturduğu etkiden daha fazla oksidatif stres parametrelerini arttırıcı bir güce sahip olabilir.

Oksidatif stres varlığında lipid peroksidasyon göstergesi MDA seviyesi çeşitli dokularda ve kan plazma/serum örneklerinde artarken, ROS eliminasyonunu sağlayan GSH ve SOD enzim aktiviteleri azalmaktadir ${ }^{38,39}$. Bu çalışmada da ardışık 2 gün aglepriston enjeksiyonu yapılan tavşanlarda plazmada MDA seviyesi yükselmiş, GSH ve SOD enzim aktivitesi azalmıştır. $\mathrm{Bu}$ sonuçlardan abortun ve/veya özellikle Aglepristonun antioksidan savunma kapasitesini düşürücü ve oksidatif stress parametreleri üzerine olumsuz etkisi görülmektedir. Ayrıca azalmış antioksidan kapasite de infertilitenin patogenezinde belirleyici bir faktör olarak rol oynayabilir.

Damasceno ve ark. ${ }^{7}$ tarafindan yapılan bir çalışmada, diyabetli sıçanlarda oksidatif streste genel bir artış ve oksidatif strese bağlı olarak da gebeliğin embriyonik ve fötal dönemlerinde de değişiklikler saptamışlardır. Ancak meydana gelen bu oksidatif stresi de diyabetle ilişkilendirmişlerdir. SOD ve GSH gibi antioksidan enzim miktarlarında düşüş saptamışlardır.

Troudi ve ark. $^{38}$ ise gebeliğin erken ve geç safhalarındaki sıçanlarda, oksidatif stresin şekillenmesini tetikleyen nörotoksik bir ajan kullanarak yaptıkları bir toksisite çalışmasında, meydana gelen oksidatif strese bağli olarak MDA seviyesinde artış ve SOD ve GSH gibi antioksidan enzimlerde düşüş saptamışlardır. 
Oksidatif stress parametrelerindeki değişiklikler bizim çalışmamızı destekler tarzdadır. Fakat bu çalışmaların her ikisinde de abort şekillenmemiştir.

Liu ve ark. ${ }^{25}$ insanlarda yaptıkları bir çalışmada erken dönem gebeliklerin sonlanmasında oksidatif stresin patolojik bir zemin hazırlayabileceğini savunmuşlardır. Artan reaktif oksijen türlerinin endoplazmik retikulumda (ER) stress olușturduğu, buna bağlı olarak ER fonksiyonunun bozulduğu, ve ER stresinin de erken dönem gebeliklerde gebeliğin sonlanmasında rolü olabileceğini vurgulamışlardır.

Gündoğan ve ark. ${ }^{19}$ ise gebe sıçanlara etanol vererek oksidatif stresin arttığ1, DNA hasarının ve lipid peroksidasyonun şekillendiği, yavrunun yaşama şansının azaldığını ve erken dönem gebeliğin sonlanma riski arttırdığını bulmuşlardır. Gebeliğin sonlanmasınıda alkolün neden olduğu oksidatif strese bağlamışlardır.

Sonuç olarak, Aglepristonun ardış1k iki gün çift enjeksiyonu sonrası hayvanların oksidatif strese daha fazla maruz kaldıkları görülmektedir. Hayvanlarda oluşan oksidatif stresin kaynağ1 Aglepristonun kendisi olabileceği gibi Aglepriston ile abort şekillenmesinden de kaynaklanabilir. Aglepristonun enjeksiyonu sonrası tavşanlarda oluşan oksidatif stresin kaynağının ve etki mekanizmasının tam olarak açıklanabilmesi için ileri tetkiklere ihtiyaç vardır.

\section{Kaynaklar}

1. Ascensao AA, Magalhaes JF, Soares JM, Ferreira RM, Neuparth MJ, Appell HJ, Duarte JA, 2005. Cardiac mitochondrial respiratory function and oxidative stress: the role of exercise. Int. J. Sports Med., 26, 258.

2. Chang CC, Wang WC, Bardin CW., 1993. Termination of earlypregnancy in therat, rabbit, andhamsterwith RU 486 andanordrin. Contraception, 47:597-608.

3. Chang CC, Wang CC, Bardin CW, 1993a. Postcoitaluse of anordrinand RU 486 forprevention of implantation in therat. Contraception, 47, 413419.

4. Chang CC, Wang CC, Bardin CW, 1993b. Termination of early pregnancy in the rat, rabbit, and hamster with RU 486 and anordrin. Contraception, 47, 597-608.

5. Chang CC, Wang CC, Bardin CW, 1993c. Anordiol is more potent than an ordrin for terminatin gpregnancy when administered with RU 486. Contraception, 47, 609-616.
6. Çaylak E.,2011. Hayvan ve bitkilerde oksidatif stress ile antioksidanlar. Tıp Araştırmaları Dergisi, 9(1), 73-83.

7. Damasceno DC, Volpato GT, Calderon IMP, Rudge MVC, 2002. Oxidative stres and diabetes in pregnant rats. Animal Rep. Sci., 72, 235-244.

8. Dao B, Vanage G, Marshall A, Bardin CW, Koide SS, 1996. Anti-implantation activity of antiestrogens and mifepristone. Contraception, 54, 253-258.

9. Demir M, Vural CD, Yılmaz N, Yüksel Ş, Vural H, Sezer MT, 2007. Tek seans hemodiyalizin çeşitli oksidatif stress markerları üzerine etkisi. Tıp Araştırmaları Dergisi, 5(2), 74-77.

10. Derviş E., 2011. Oral antioksidanlar. Dermatoz, 2(1), 263-267.

11. Dursun E, Özben T, Süleymanlar G, Dursun B, Yakupoğlu G, 2002. Effect of hemodialysis on the oxidative stress and antioxidants. Clin. Chem. Lab. Med., 40,1009-1013.

12. Ellman GL., 1959. Tissue sulfhydryl groups. Arch. Biochem. Biophys., 82:70-7.

13. Fieni F, Tainturier D, Bruyas JF, Bdinand F, Berthelot X, Ronsin P, Rachail M, Lefay MP., 1996. Etudecliniqued'une antihormonepourprovoquerl'avortementchez la chienne. Recueil de Me'decineVe'te'rinaire, 172:359-67.

14. Fieni F, Martal J, Marnet PG, Siliart B, Bernarnd F, Riou M, Bruyas JF, Tainturier D., 2001. Hormonalvariation in bitchesafterearlyormidpregnancyterminationwithaglepristone (RU534). J ReprodFertilSuppl, 57:243-8.

15. Fieni F, Martal J, Marnet PG, Siliart B, Guittot F., 2006. Clinical, biologicalandhormonalstudy of mid-pregnancytermination in catswithaglepristone. Theriogenology, 66:1721-8.

16. Galac S, Kooistra HS, Butinar J, Bevers MM, Dieleman SJ, Voorhout G, Okkens AC., 2000. Termination of mid-gestation pregnancy in bitches with aglepristone, a progesterone receptor antagonist. Theriogenology, 53:941-50.

17. Georgiev P, Wehrend A., 2006. Mid-gestation pregnancy termination by the progesterone receptor blocker aglepristone in queens. Theriogenology, 65:1401-6.

18. Georgiev P, Wehrend A, Penchev G, Vodenicharov A, Kauffold J, Leiser R. Histologicalchanges of thefelinecervix, endometrium and placenta after mid-gestational termination of pregnancy with aglepristone. Reprod. Domes Anim; baskida.

19. Gündoğan F, Elwood G, Mark P, Feijoo A, Longato L, Tong M, Monte SM, 2010. EthanolInduced Oxidative Stress and Mitochondrial Dysfunction in Rat Placenta: Relevance to Pregnancy Loss. Alcohol Clin. Exp. Res., 34(3), 415-423. 
20. Halliwell B, Gutteridge JMC, 1999. Free radicals, other reactive species and disease in Free Radicals in Biology and Medicine, edited by Halliwell, B \& Gutteridge, J.M.C, (Oxford University Press: New York, USA), sf.639.

21. Hoffmann B, Schuler G., 2000. Receptor blockers-general aspects with respect to their use in domestic animal reproduction. Anim Reprod Sci., 60/61:295-312.

22. Hubler M, Arnold S., 2000. Prevention of pregnancy in bitches with the progesterone antagonist aglepristone (alizine). SchweizerArchivfürTierheilkunde, 142:381-6.

23. Klemm A, Voigt C, Friedrich M, 2001. Determination of erythrocyte antioxidant capacity in haemodialysis patients using electron paramagnetic resonance. Nephrol. Dial. Transplant., 16, 21662171.

24. Koca N, Karadeniz F., 2002. Serbest radikal oluşum mekanizmaları ve vücuttaki antioksidan savunma sistemleri. Gıda Mühendisliği Dergisi.

25. Liu AX, He WH, Yin LJ, Lv PP, Zhang Y, Sheng JZ, Leung PCK, Huang HF, 2011. Sustained Endoplasmic Reticulum Stress as a Cofactor of Oxidative Stress in Decidual Cells from Patients with Early Pregnancy Loss. J. Clin. Endocrinol Metab., 96(3), E493-E497.

26. Morena M, Cristol JP, Bosc JY, 2002. Convective and diffusive losses of vitamine $\mathrm{C}$ during haemodiafiltration session: a contributive factor to oxidative stres in haemodialysis patient. Nephrol. Dial. Transplant., 17,422-427.

27. Ohkawa H, Ohishi N, Yagi K., 1979. Assayforlipidperoxides in animal tissues by thiobarbituricacid reaction. Anal Biochem, 95:351-8.

28. Özalp GR, Seyrek-Intas, K, Calıskan C, , Wehrend A, 2008. Mid-gestation pregnancy termination in rabbits by the progesterone antagonist aglepristone. Theriogenology, 69, 1056-1060.

29. Özalp GR., Çalışkan Ç., Seyrek-İntaş K., Wehrend A., 2010. Effects of the progesterone receptor antagonist aglepristone in implantation administered on days 6 and 7 after mating in rabbits. Reprod. Dom. Anim., 45, 505-508; doi: 10.1111/j.1439-0531.2008.01282.x
30. Özalp GR, Temizel EM, Ozocak-Batmaz E., 2013. Clinical, ultrasonography and haematology of aglepristone-induced mid-gestation pregnancy terminations in rabbits. J S Afr Vet Assoc. May, 6;84(1):E1-5. doi: 10.4102/jsava.v84i1.998.

31.31.Özden M, Maral H, Akaydın D, Çetinalp P, Kalender B, 2002. Erythrocyte glutathione peroxidase activity, plasma malondialdehyde and erythrocyte glutathione levels in hemodialysis and CAPD patients. Clin. Biochem., 35,269-273.

32. Philibert D., 1994. RU 46534 Affinite' relative de liaisonpourlesre'cepteursste'roidiens- activite' antiprogeste'rone in vivo. Rapportd'e'tude interne Roussel Uclaf.

33. Saksena SK, Chang MC, Lau IF., 1979. Termination of pregnancy in rabbit and mouse by Trichosanthin. Contraception, 20:367-76.

34. Salomy M, Golstein PJ, 1978. Prevention of pregnancy in rabbit sus ingvaginal application of prostaglandin F2a. Fertil Steril, 29, 456-458.

35. Sies H.,1993. Strategies of antioxidant defense. Eur. J. Biochem., 215, 213-219.

36. Steiger K, Politt E, Hoeftmann T, MeyerLindenberg A, Schoon HA, Guenzel-Apel AR., 2006. Morphology of canine placental sites after induced embryonic or fetal death. Theriogenology, 66:1709-14.

37. Sun Y, Oberley LW, Li Y., 1988. A simple method for clinical assay of superoxide dismutase. Clin. Chem., 34:497-500.

38. Troudi A, Bouaziz H, Soudani N, Amara IB, Boudawara T, Touzani H, Lyoussi B, Zeghal N, 2012. Neurotoxicity and oxidative stress induced by gibberellic acid in rats during late pregnancy and early postnatal periods: Biochemical and histological changes. Experimental and Toxicologic Pathology, 64, 583-590.

39. Uzun D, Korkmaz GG, Sitar ME, Cebe T, Yanar K, Çakatay U, Aydın S., 2013. Oxidative damage parameters in renal tissues of aged and young rats based on gender. Clinical Interventions in Aging, $8,809-815$ 